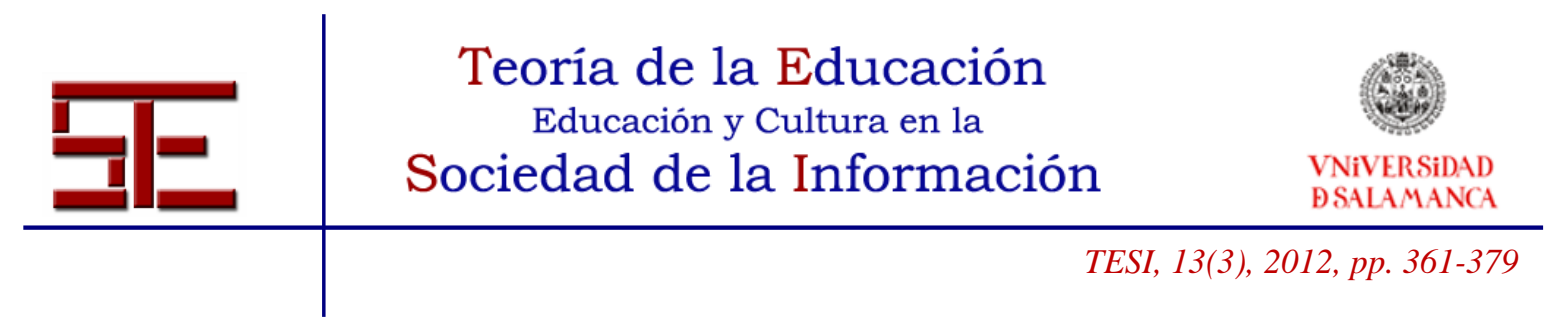

\title{
¿POR QUÉ ES NECESARIO REALIZAR UNA EDUCACIÓN MEDIÁTICA? UN ANÁLISIS DE CASO CON LA PELÍCULA COBARDES
}

Resumen: El presente artículo pretende demostrar la necesidad de incorporar al currículo la educación mediática para que los alumnos puedan aplicarla cuando consuman contenidos mediáticos. Así, se ha utilizado para la investigación realizada una película dirigida al público adolescente, Cobardes (Juan Cruz y José Corbacho, 2008) y se ha analizado su mensaje en relación a la violencia. Mediante una encuesta realizada y analizando los resultados con la ayuda de la estadística, se ha podido demostrar que, a pesar de que es una película recomendada para mayores de 13 años, es necesario un visionado con mediación parental o escolar.

Palabras clave: Educación mediática; medios de comunicación, cine; Cobardes; televisión.

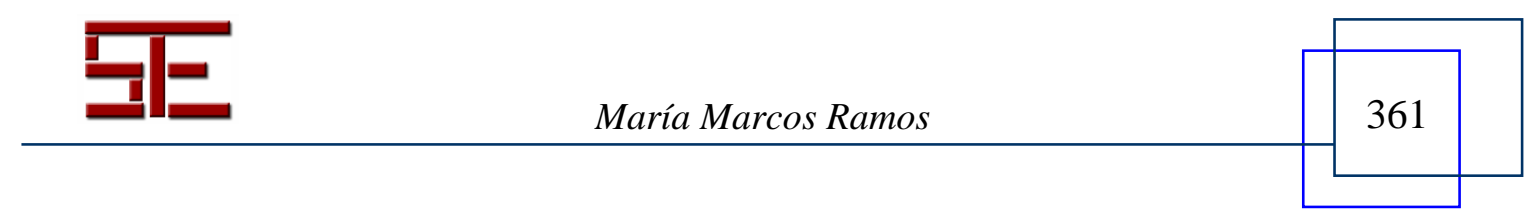




\title{
WHY IS IT NECESSARY MEDIA EDUCATION? AN ANALYSIS OF CASE BY
} THE FILM COBARDES

\begin{abstract}
The present article tries to demonstrate why is need to incorporate media education into the curriculum so that students can apply when they consume content media. It has been used for research on a film directed at teenagers, Cobardes (Juan Cruz y José Corbacho, 2008), and analyzed post in relation to violence. Through a survey and analyzing the results with the help of statistics, it has been shown that, although it is a movie recommended for over 13 years, is required viewing with parental or school mediation.
\end{abstract}

Keywords: Media Education; Media; Film; Cabardes; Television. 


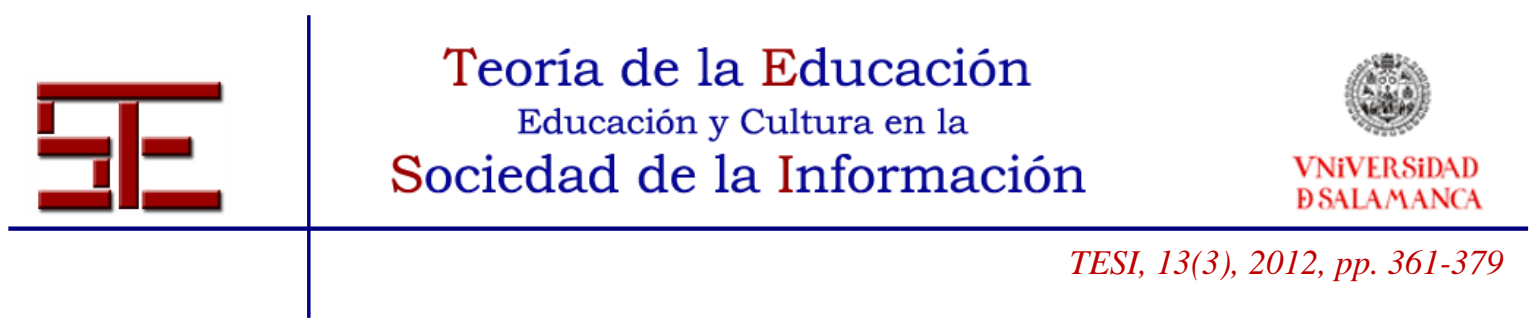

\title{
¿POR QUÉ ES NECESARIO REALIZAR UNA EDUCACIÓN MEDIÁTICA? UN ANÁLISIS DE CASO CON LA PELÍCULA COBARDES
}

Fecha de recepción: 10/01/2012; fecha de aceptación: 29/10/2012; fecha de publicación: 30/11/2012

\author{
María Marcos Ramos \\ mariamarcos@usal.es
}

Universidad de Salamanca

\section{1.- INTRODUCCIÓN}

Los medios de comunicación se han convertido, junto a la experiencia directa, en el principal instrumento de construcción de la realidad. Influyen en nuestras opiniones, ideas, comportamientos..., construyen nuestro universo simbólico, nos moldean y nos influyen. Vivimos rodeamos de información, de imágenes, de textos y de mensajes. Se hace por tanto necesario e imprescindible en la sociedad en la que vivimos, la denominada sociedad de la información, enseñar a niños y a adolescentes cómo leer las imágenes, cómo interpretarlas, cómo interactuar con los medios de comunicación, con las nuevas tecnologías... Se hace fundamental, en definitiva, una alfabetización mediática. Los adolescentes de hoy serán receptores, y puede que también generadores de contenidos, en el futuro. Es preciso darles las estrategias necesarias que les permitan diferenciar qué es bueno y qué es malo en los medios de comunicación.

Por otro lado, no debemos olvidar que son muchos los docentes que han incluido entre sus programaciones didácticas la utilización de películas para poder tratar determinados temas, haciendo uso del denominado "cine formativo". Así, han proliferado los manuales en los que se hacen una serie de recomendaciones sobre películas y temas para que los profesores los utilicen en sus clases. Saturnino de la Torre $(1997,17)$ define el cine formativo "como la emisión y recepción intencional de películas portadoras de valores culturales, humanos, técnico-científicos o artísticos, con la finalidad de mejorar el conocimiento, las estrategias o las actitudes y opiniones de los espectadores".

Además, en un estudio, Del Río, Álvarez y Del Río (2004) señalaron que para los espectadores de 4 a 12 años las películas eran una de sus preferencias de visualización -siendo la tercera opción seleccionada por un $20 \%$ de los encuestados,

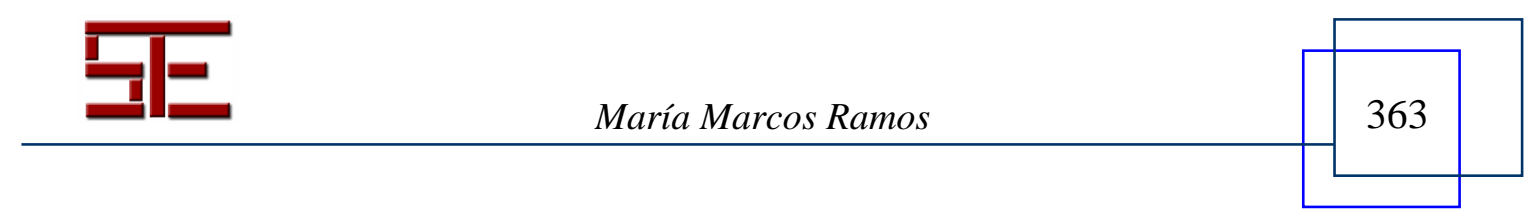




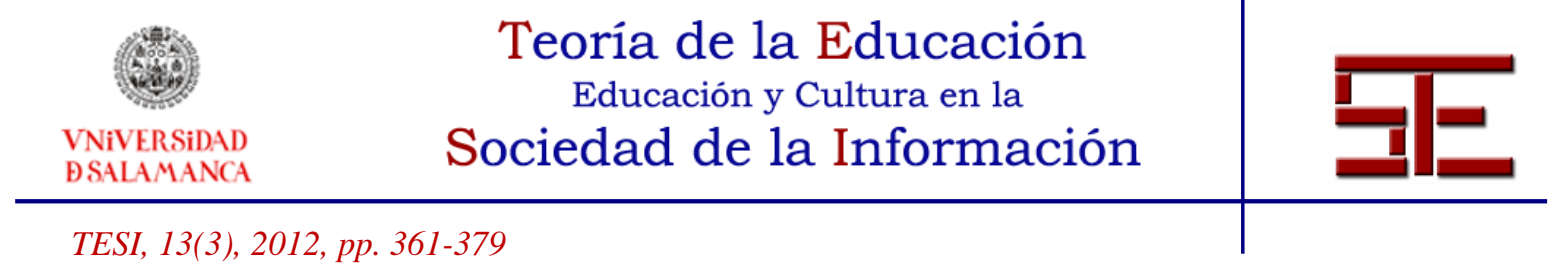

cuyas primera y segunda opción, respectivamente, eran las series de producción propia y la programación propiamente infantil y juvenil, especialmente dibujos animados y programas específicos-. Las películas ocupaban la primera opción entre los encuestados de entre 13 y 24 años, siendo elegidas por un $29 \%$ de los encuestados a la hora de ver contenidos televisivos.

Dado que las películas son programas que se seleccionan con una muy alta preferencia por parte de los espectadores, se ha seleccionado una película para esta investigación cuya base era un cuestionario elaborado para la ocasión que se debía completar una vez realizado el visionado. Los participantes debían completar una encuesta autoadministrada en la que "es el mismo sujeto el que cumplimenta el cuestionario (...) Los sujetos reciben un cuestionario (...) y lo deben cumplimentar sin que medie entrevista alguna. A pesar de todo se podrá contar con la ayuda de las personas que han entregado ese cuestionario" (Igartua, 2006, 292).

\section{2.- PELÍCULA COBARDES}

Cobardes $^{1}$ es una película que bien podría haberse emitido en la televisión, pero que también es accesible por otros medios de comunicación, como puede ser un portal de Internet. Además, es una película que desde su página web propone una guía didáctica de utilización para el aula y se ha convertido en uno de los recursos que profesores, pedagogos y educadores más están utilizando en las aulas para tratar el tema del acoso escolar, por lo que resulta fundamental comprobar si el mensaje de la película es el adecuado para combatir desde el aula un tema de violencia, más en concreto, de violencia escolar. Se debía, por tanto, comprobar hasta qué punto la película Cobardes reúne las características que Saturnino de la Torre señala que deben tener las películas que se utilicen como cine formativo,

En primer lugar, han de poseer determinados valores o méritos humanos; en segundo lugar estar codificados de forma que sean interpretables y en tercer lugar que exista una intención de utilizar dicho medio como recurso formativo, es decir, con voluntad de producir algún tipo de aprendizaje, que no tiene por qué estar vinculado necesariamente al mensaje de la película (De la Torre, 1997, 17).

Así, el objetivo de este estudio era analizar el mensaje cultivado por la película Cobardes para comprobar si el criterio de edad era el adecuado. Además, se pretendía analizar si la película es apropiada para los adolescentes, especialmente para aquellos que realizan un visionado sin control y/o mediación parental.

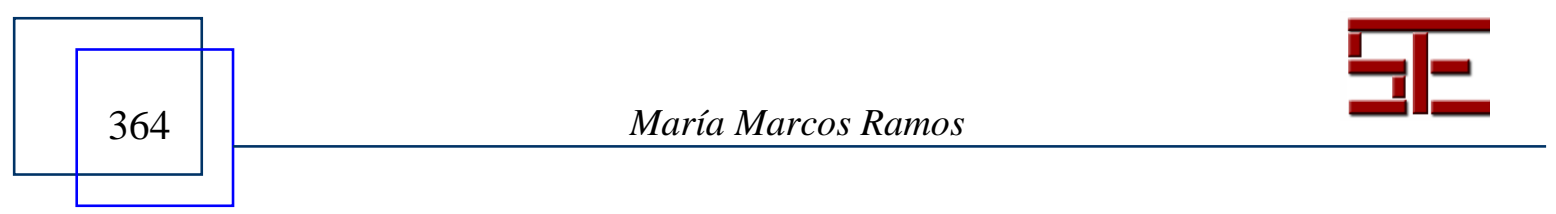




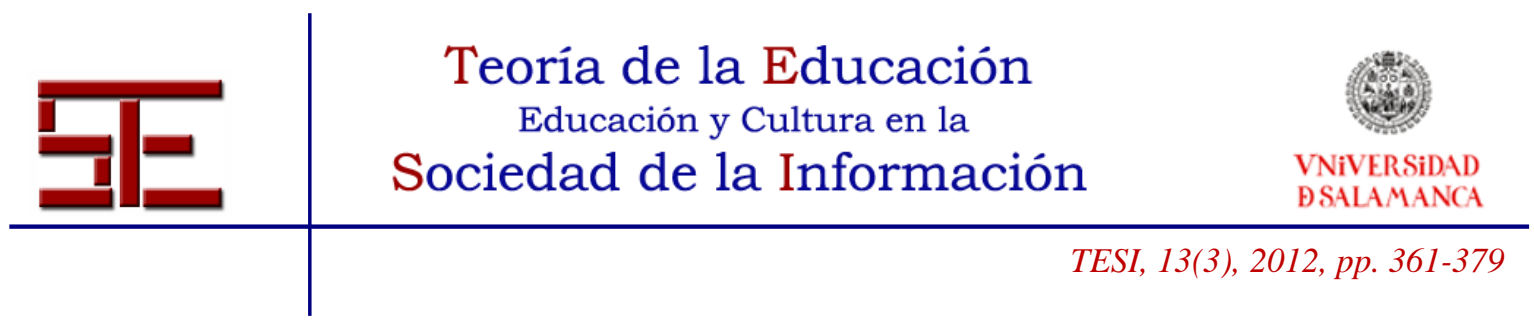

Cobardes es la segunda incursión cinematográfica de Juan Cruz y José Corbacho tras Tapas. Protagonizada, entre otros, por Elvira Mínguez, Lluís Homar, Paz Padilla, María Molins, Eduardo Espinilla, Ariadna Gaya, Javier Bódalo y Eduardo de la Torre, cuenta la historia de Gaby, un chaval de catorce años que tiene miedo a ir al colegio. Tal vez el culpable de su miedo sea Guille, un compañero de clase, que tiene miedo de defraudar a sus padres. Los padres de Gaby y Guille también tienen miedo, miedo a perder el trabajo, miedo de conocer a sus hijos, miedo a no saber ayudarles... Cobardes es, pues, una historia que habla del miedo, del miedo y de la violencia escolar en la que se ven envueltos sus protagonistas.

Los protagonistas de la película y sobre los que gira la historia son Gaby y Guille, dos alumnos de secundaria. Guille es en apariencia un alumno más, con buenas notas, buen deportista y de buena familia, pero que en clase y ante su grupo de amigos actúa como líder ejerciendo la violencia e intimidando a sus compañeros, en este caso, a Gaby. La excusa para ser acosado no es otra que ser pelirrojo. Éste será el punto de partida de la película y a partir del cual giran el resto de los personajes, las familias y compañeros de Gaby y Guille.

Los otros personajes de la película son los padres Gaby y Guille. La madre de Gaby, Merche, es una periodista que adora su trabajo aunque le quita mucho tiempo para ocuparse de sus hijos. A pesar de esto, sospecha desde el primer momento que algo le sucede a su hijo y le apoya en todas las decisiones que toma a pesar de no saber muy bien de qué se trata. El padre de Gaby, Joaquín, vive angustiado por su situación laboral en la empresa. Le cuesta enfrentarse a lo que realmente importa en su casa y no entiende qué le sucede a su hijo. Los padres de Guille pertenecen a una clase social alta ya que el padre de Guillermo tiene un cargo político, es concejal de Seguridad Ciudadana. Debido a su posición política, debe llevar escolta. En ningún momento se da cuenta de la situación del hijo. Magda, la mujer de Guillermo y madre de Guille, sospecha que algo pasa con su hijo viviendo esta situación con cierta aprensión. Sabe que su hijo no se está comportando bien y tiene miedo a que el control de su familia se le escape de las manos.

También tienen un peso específico en la historia y, por tanto, en la película, los amigos de Gaby y Guille. Chape, Gorka y Javi son amigos e integrantes del grupo de acosadores que lidera Guille, aunque ésta no es una relación de amistad convencional, ya que está basada en el miedo que tienen a Guille y que les haga a ellos lo mismo que hace y hacen a Gaby. Carla, por su parte, es amiga de Gaby. Sabe lo que le sucede e

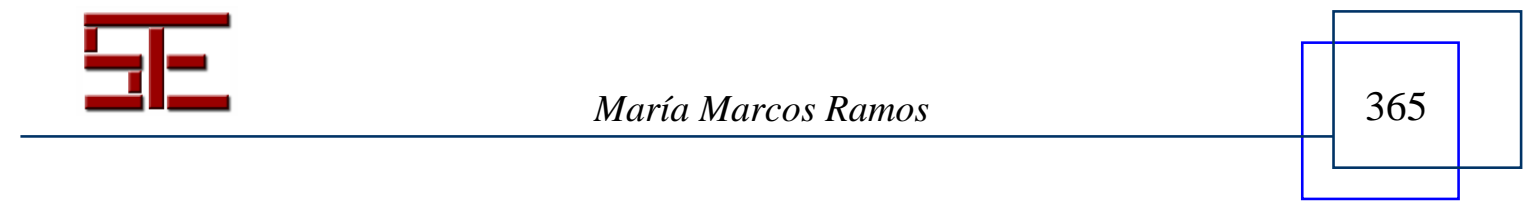




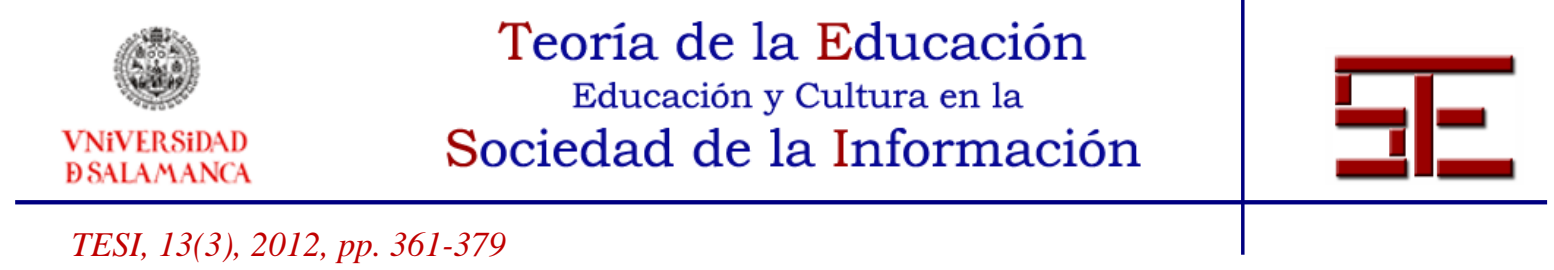

intentará ayudarle, aunque no esté muy de acuerdo con las decisiones y aptitudes de Gaby.

La película trata no solo del acoso escolar, sino que también trata el tema de la violencia en el entorno escolar y de la utilización de la violencia como modo de resolver conflictos. Son numerosos los estudios realizados en el campo de las ciencias sociales sobre los efectos negativos de la violencia mediática. Ya en los años veinte, el Consejo de Investigación sobre Imágenes en Movimiento (1928) realizó una serie de investigaciones sobre la influencia de las películas en los niños utilizando el análisis de contenido llegando a la conclusión de que las películas incitaban conductas sociales negativas (Wimmer y Dominick, 1996, 358). Diversos autores desde diferentes perspectivas han investigado sobre los efectos de la violencia mediática en los niños y adolescentes. Se han realizado estudios basados en los efectos conductuales, los cuales se centran en tres vertientes: imitación, desinhibición y catarsis. Entre los autores que han trabajado bajo estas premisas se puede señalar a Bandura, Ross y Ross (1963), Berkowitz (1965), Feshback (1963), Feshback y Singer (1971), entre otros. Liebert y Baron (1972), Drabman y Thomas (1974), Thomas, Horton, Lippincott y Drabman (1977), Geen y O’Neal, (1969), Huston, Fox, Green, Watkins y Whitaker (1981), Potts, Huston y Wright, (1986), Josephson, (1987), etc., han realizado estudios basados en los efectos afectivos de la violencia televisiva en los niños, de los que destacan dos tipos: los de desensibilización y los de estimulación o excitación. Los estudios basados en los efectos cognitivos de la violencia televisiva en los niños, en los que se fundamenta la Teoría del aprendizaje observacional o Teoría social del aprendizaje, han sido desarrollados por Bandura (1977), Lefkowitz et al. (1972), Milavsky et al. (1981), Huesmann y Eron (1986), etc.

\section{3.- INVESTIGACIÓN REALIZADA}

La película seleccionada para este estudio es Cobardes. Los motivos por los cuales se ha trabajado con este filme son varios. En primer lugar, es una película con la que los docentes están trabajando en las aulas para tratar el acoso escolar, también denominado bullying, cada vez con mayor presencia no sólo en los medios de comunicación, sino también en las aulas, siendo una de las problemáticas que más preocupan a docentes y a padres. Es un tema, además, cercano a los adolescentes y que por tanto se puede abordar fácilmente y está muy relacionado con la violencia, una violencia muy cercana a los adolescentes y con la que se pueden sentir fácilmente identificados. Además, Cobardes presenta a los jóvenes en un escenario de actividad separado o segregado del de los

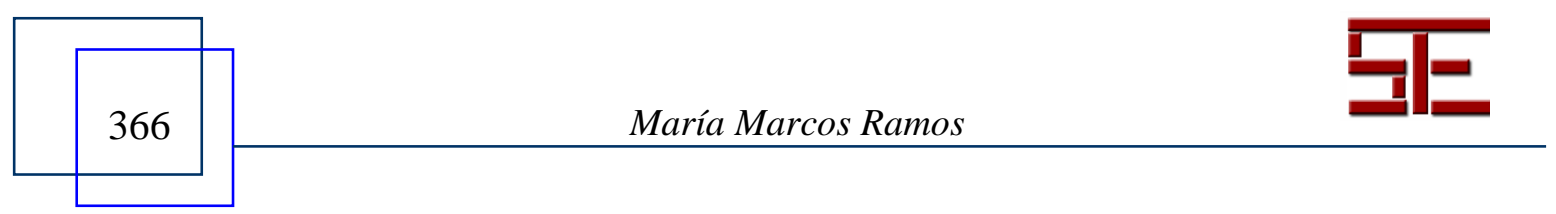




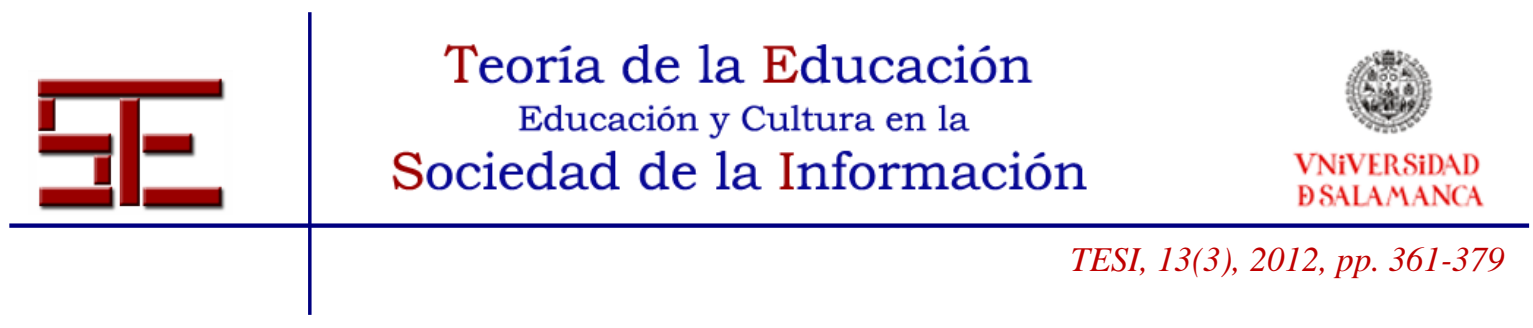

adultos, en una ignorancia mutua. Es, además, una de las características que más se da en la denominada programación infantil/juvenil, en la que son los "contenedores infantiles los que más se alejaban de un sistema de mundo/actividad integrado y presentaban al niño o al joven por separado, en un mundo propio" (Del Río, Álvarez, Del Río, 2004).

Otra de las variables que se tuvo en cuenta a la hora de realizar la selección fue la duración. Se buscaba que la película no sobrepase, a ser posible, la hora y media de metraje, ya que la cantidad de información a suministrar por la película no debe ser excesiva para una correcta asimilación, además que debe mantener el nivel de atención del espectador. Hay que añadir que si la película va a ser utilizada en el aula por un docente para trabajar algún aspecto clave, la película no debe ser excesivamente larga, como mucho debería ocupar dos clases de una hora, ya que de esta manera se puede ver y trabajar en dos horas. Además, se pretendía que fuese lo más amena posible teniendo en cuenta la duración de la misma. Cobardes es una película muy actual, del 2008, en la que los protagonistas son adolescentes convencionales. No son niños marginales, ni excesivamente conflictivos, sino que son personajes que se comportan como la mayoría de los adolescentes españoles. Se buscaba una identificación muy alta entre los actores y los adolescentes y, en este sentido, Cobardes logra esta identificación.

La película fue sometida a un estudio con el fin de evaluar el mensaje cultivado. En el estudio participaron 10 personas a las cuales se les pidió que viesen la película y que contestaran a un cuestionario sobre el mensaje cultivado por Cobardes. La investigación tuvo como base un cuestionario que contenía varias escalas autoaplicadas elaboradas para la ocasión que pretendían medir el mensaje cultivado por la película. Una de las reglas que todo cuestionario debe cumplir (Igartua, 2006) es que sean relativamente pocas las preguntas. En este caso, así se realizó siendo cuatro las preguntas a contestar por los participantes. Las preguntas eran relevantes para la investigación y estaban presentadas en batería (Igartua, 2006). Sobre los participantes, se buscaba una muestra no demasiado amplia para poder probar la consistencia interna del cuestionario, de cara a realizar un estudio que contase con un mayor número de participantes. Esta práctica es habitual en las investigaciones experimentales ya que se debe comprobar la validez del cuestionario. La investigación tenía una limitación añadida: la película no había contado con el respaldo del público a pesar de que, en el Festival de Málaga del 2009, Cobardes fue galardonada con el Premio de la Crítica y obtuvo la Mención Especial del Jurado. Se realizó primero una búsqueda entre conocidos para ver quiénes habían visto la película. De esta búsqueda, se seleccionaron

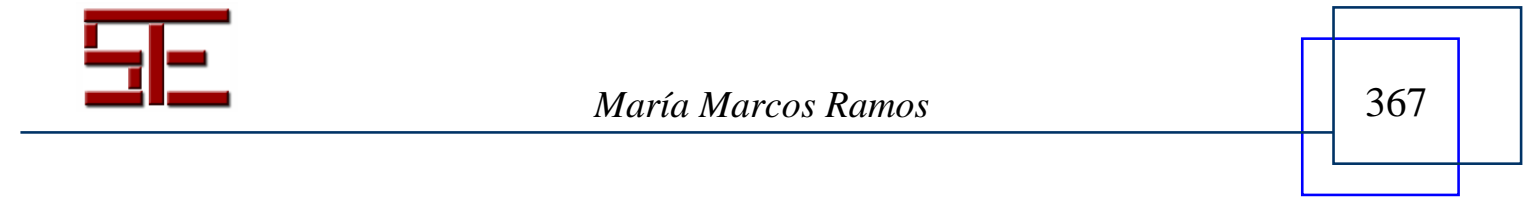




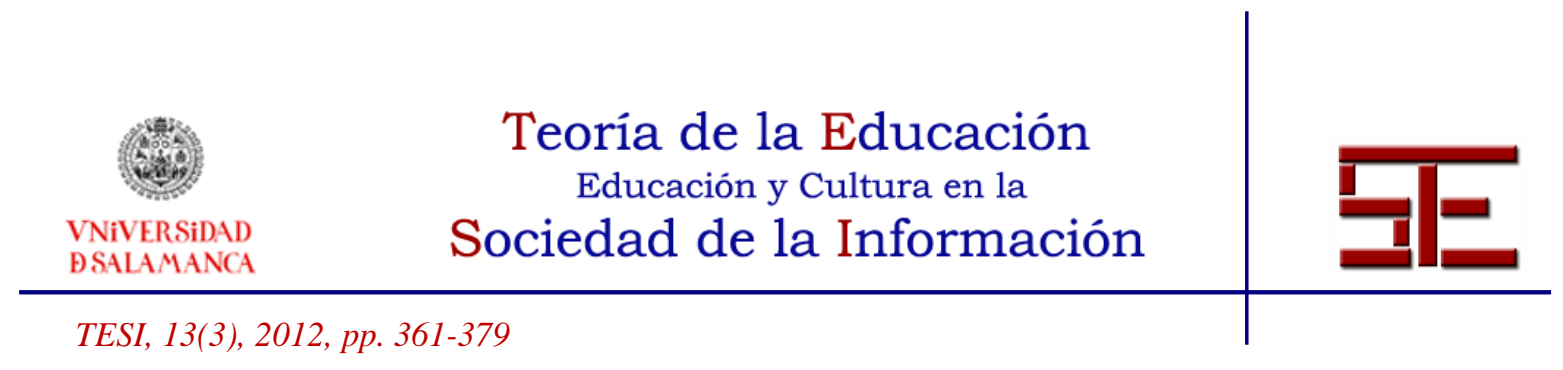

10 participantes: 4 mujeres y 6 hombres, todos ellos con estudios superiores, de un entorno urbano. El rango de edad de los participantes va de 23 a 45 años. De los 10 participantes, 4 son profesores -3 universitarios y 1 de educación primaria-, 2 son estudiantes y el resto de diversas ocupaciones -arquitectura, administración, marketing, etc.-. Además, cuatro de las participantes tienen hijos, con lo que la película les interesaba especialmente. Las preguntas que se realizaron fueron 4:

1- Según tu opinión personal, y después de haber visto Cobardes, ¿en qué medida crees que se proyecta, refuerza o cultiva una imagen de la violencia como algo...? El formato de respuesta era una escala de 11 ítems que va desde 0 (muy negativo) a 10 (muy positivo).

2- ¿En qué medida consideras que la película Cobardes refuerza cada una de las siguientes ideas sobre la violencia? Las ideas sobre las que se preguntaba eran: "la violencia se resuelve con violencia", "la violencia no hay que denunciarla", "los conflictos hay que solucionarlos con el grupo de iguales y no con los padres", "la violencia es mejor silenciarla para que se reduzca" y "es mejor dejar que maltraten a otros antes que a mí". Para cada uno de los ítems, se debía indicar si la idea estaba en la película Cobardes "nada presente (1)", "poco presente (2)", "algo presente (3)", "bastante presente (4)" y "muy presente (5)".

3. Según tu opinión personal, ¿en qué medida la película Cobardes induce o provoca las siguientes reacciones emocionales hacia la violencia? Las reacciones emocionales a tener en cuenta eran: miedo, inseguridad, indiferencia, admiración y valentía. Se debía indicar en qué grado estaba presente entre los siguientes: nada (1), poco (2), algo (3), bastante (4) y mucho (5).

4. Según tu opinión personal, ¿en qué medida la película Cobardes refuerza las siguientes características de la violencia? Los sujetos debían indicar con nada (1), poco (2), algo (3), bastante (4) y mucho (5) si la violencia era legítima, necesaria y parte de la vida según la película Cobardes.

Los resultados de este análisis sobre Cobardes señalan que la película ofrece una imagen de la violencia bastante negativa con una media de 1.78 y una desviación típica de 1.09 -a partir de aquí se señalará la media con la inicial M y la desviación típica con

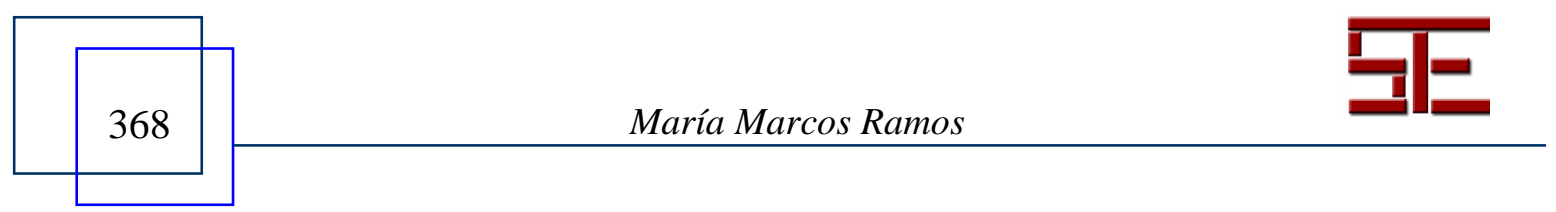




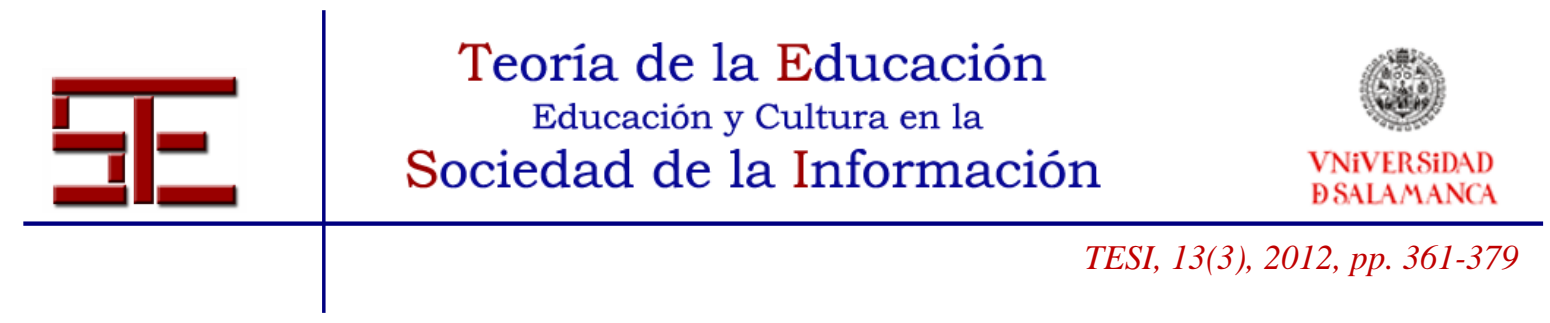

DT-. Ninguno de los participantes valoró positivamente la imagen de la violencia que proyecta la película.

Sobre la segunda pregunta relativa a las ideas que refuerza la película Cobardes las respuestas fueron las siguientes. En el ítem "la violencia se resuelve con violencia" $(\mathrm{M}=3.56 ; \mathrm{DT}=1.01)$ los encuestados consideraron que estaba bastante presente. En el ítem "la violencia no hay que denunciarla" $(\mathrm{M}=2.76$; $\mathrm{DT}=0.86)$ la mayoría de los encuestados consideran que está poco presente en la película esta idea. La idea de que "los conflictos hay que solucionarlos con el grupo de iguales y no con los padres" $(\mathrm{M}=3.76 ; \mathrm{DT}=1.11)$ está bastante presente en la película. El ítem "la violencia es mejor silenciarla para que se reduzca" $(\mathrm{M}=2.89 ; \mathrm{DT}=1.36)$ está poco presente en la película. La última idea sobre la que se preguntaba a los encuestados era "es mejor dejar que maltraten a otros antes que a mí" $(\mathrm{M}=3.44$; $\mathrm{DT}=1.42)$ los encuestados consideran que está muy presente en la película.

En lo que respecta a la tercera pregunta -reacciones emocionales hacia la violencia según la película Cobardes- las medias son las siguientes: miedo $(\mathrm{M}=4.00$; $\mathrm{DT}=1.00)$; inseguridad $(\mathrm{M}=3.89 ; \mathrm{DT}=0.78) ;$ indiferencia $(\mathrm{M}=2.89 ; \mathrm{DT}=1.53)$; admiración $(\mathrm{M}=1.78 ; \mathrm{DT}=0.66)$ y valentía $(\mathrm{M}=1.89 ; \mathrm{DT}=0.92)$ en la película.

La última pregunta trataba de averiguar en qué medida estaban presentes en la película tres características de la violencia -legítima $(\mathrm{M}=2.56$; $\mathrm{DT}=1.42)$, necesaria $(\mathrm{M}=3.00 ; \mathrm{DT}=1.22)$ y parte de la vida $(\mathrm{M}=4.00 ; \mathrm{DT}=1.22)$ - según los encuestados.

Tabla 1.1.: Mensaje cultivado por la película Cobardes en relación con la violencia

\section{Variables}

Media Desviación t0ípica

Actitud global sobre la imagen de violencia cultivada por la $1.78 \quad 1.09$ película Ideas reforzadas sobre la violencia en la película

- La violencia se resuelve con violencia $\quad 3.56 \quad 1.01$

- La violencia no hay que denunciarla $\quad 2.67 \quad 0.86$

· Los conflictos hay que solucionarlos con el grupo de iguales y $3.67 \quad 1.11$ no con los padres

- La violencia es mejor silenciarla para que se reduzca $\quad 2.89 \quad 1.36$

- Es mejor dejar que maltraten a otro antes que a mí $\quad 3.44 \quad 1.42$

Reacciones emocionales que induce la película hacia la violencia

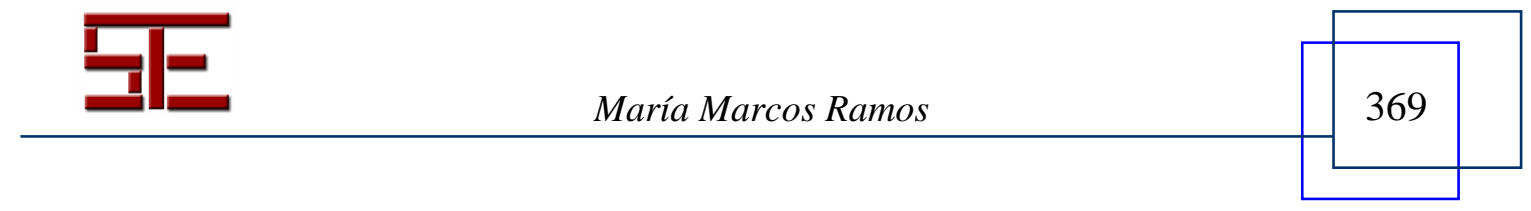




Teoria de la Educación
Educación y Cultura en la
$\begin{aligned} & \text { VNiVERSIDAD } \\ & \text { DSALAMANCA }\end{aligned}$

\begin{tabular}{lcc}
\hline Miedo & 4.00 & 1.00 \\
\hline - Inseguridad & 3.89 & 0.78 \\
\hline - Indiferencia & 2.89 & 1.53 \\
\hline - Admiración & 1.78 & 0.66 \\
\hline · Valentía & 1.89 & 0.92 \\
\hline Características de la violencia reforzadas por la película & & \\
· Legítima & 2.56 & 1.42 \\
\hline - Necesaria & 3.00 & 1.22 \\
\hline Parte de la vida & 4.00 & 1.22 \\
\hline
\end{tabular}

A modo de conclusión, Cobardes no muestra una buena imagen de la violencia. Además refuerza las ideas de que la violencia se resuelve con violencia, que no hay que denunciarla y que los conflictos se resuelven con el grupo de iguales y no con los padres. También la película refuerza la idea de que la violencia es mejor silenciarla para que se reduzca y, de forma muy significativa, que es mejor que maltraten a otros antes que a mí. La película produce en los espectadores miedo, inseguridad e indiferencia y no reacciones emocionales con carga positiva como pueden ser la admiración o la valentía. En Cobardes se ven reforzadas de forma muy significativa las siguientes características de la violencia: parte de la vida y necesaria. En menor medida se proyecta una imagen de la violencia como legítima.

\section{4.- DISCUSIÓN DE RESULTADOS: EDUCACIÓN MEDIÁTICA: QUÉ ES Y POR QUÉ REALIZARLA}

Si los adolescentes hubiesen visto la película Cobardes solos, sin que hubiese existido mediación y/o contextualización, podrían haber aprendido un comportamiento erróneo de la película. Gaby, un alumno de su misma edad con el que pueden tener cercanía personal, ante una situación de acoso que sufre -como la que puede darse en cualquier centro escolar- no se comporta de manera adecuada ya que en vez de acudir a los adultos, ya sean padres o profesores, para que le ayuden a resolver la situación decide actuar por su cuenta utilizando la violencia para resolver el conflicto. Además, al final de la película, se intuye que deja de ser acosado para convertirse en acosador. El receptor puede sacar la siguiente lectura de la situación: la única manera de sobrevivir es ser como ellos y es mejor pegar a otros antes que me peguen a mí. Éste podría haber sido, perfectamente, el aprendizaje que el espectador, en este caso un niño o adolescente, hubiera hecho de la película. Si el visionado se hubiese producido, además, sin la asistencia de un adulto que le diga que el comportamiento de Gaby no es el

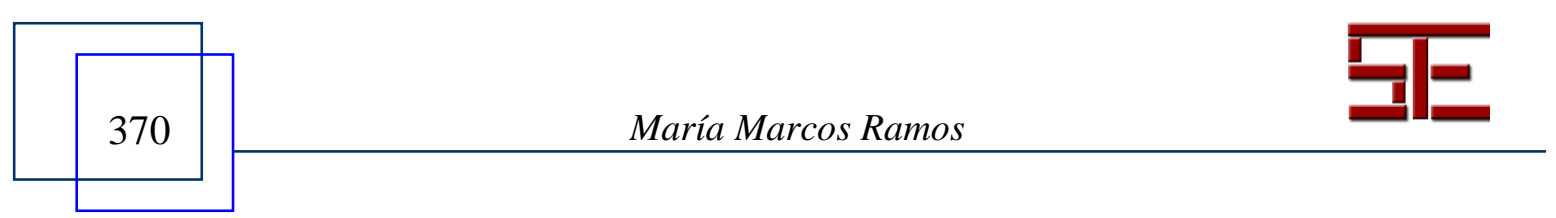




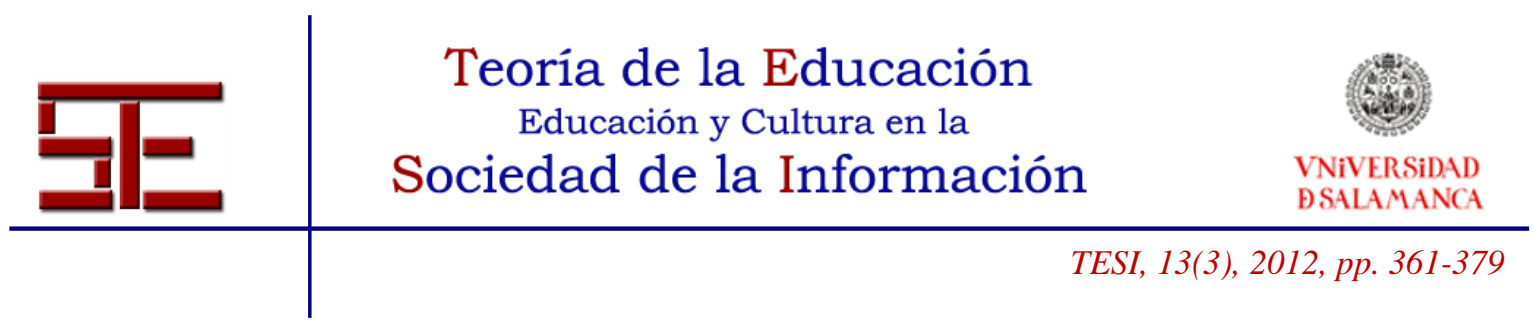

correcto ni es el que se debe de hacer, el alumno habría hecho un mal uso del contenido mediático, en este caso, de la película. Sin embargo, si el niño y/o adolescente hubiese tenido las herramientas necesarias - una buena alfabetización mediática- o un adulto que guiase el visionado realizando un visionado crítico del mismo, resaltando los valores positivos y recriminando los negativos, habría adquirido un aprendizaje positivo.

Se hace necesario, ya que vivimos rodeados de información y de medios de comunicación que nos la ofrecen, diseñar unas políticas educativas, tanto dentro de la escuela como en el entorno que nos rodea, que se ocupen de la llamada alfabetización digital. En la escuela se nos enseña a leer y a escribir, pero esta alfabetización denominada analógica- no se limita sólo a que sepamos diferenciar una letra de otra, a que sepamos cómo suena si juntamos una "c" con una "a", esta alfabetización va más allá. Olson $(1995,75)$ ha señalado que

la escritura no es una mera trascripción del habla, sino que más bien proporciona un modelo conceptual para el habla (...) [y que] las escrituras como sistemas simbólicos emergentes en sí mismos que intentan ajustarse dificultosamente y que interactúan con el sistema simbólico del habla. Y al hacerlo, al aprender a leer y escribir, aprendemos un o unos sistemas simbólicos distintos del habla y que a la vez nos sirven como una especie de modelo de contraste para comprender ésta, para pensar en el lenguaje oral.

Así, al igual que en la escuela se enseña a leer y a escribir, se hace necesaria la incorporación dentro del currículum de la alfabetización audiovisual o mediática

abarcando un amplio espectro de competencias necesarias en el entorno representacional complejo actual y con una perspectiva multialfabetizadora. Deberá contemplarse la alfabetización mediática no sólo en relación con los aspectos de los medios y los lenguajes audiovisuales, sino atendiendo también a los grandes procesos de desarrollo mental: atención, educación perceptiva (pictorial consciousness), estructuras de representación, factualidad y realismo (social, narrativa, drama, etcétera). (...) sería preciso realizar un trabajo interdisciplinar con especialistas de la educación, la comunicación y el desarrollo, para abordar ambas iniciativas (Del Río, Álvarez, Del Río, 2004).

Al igual que pasa con la lectura, las matemáticas u otras disciplinas, el consumo mediático -ver televisión, películas, leer cómics, periódicos, revistas, navegar por Internet...- no genera por sí solo competencias mediáticas, salvo de bajo nivel. Las competencias alfabéticas de alto nivel se benefician de una enseñanza articulada entre alfabetización verbal y alfabetización mediática, audiovisual, digital y otras alfabetizaciones.

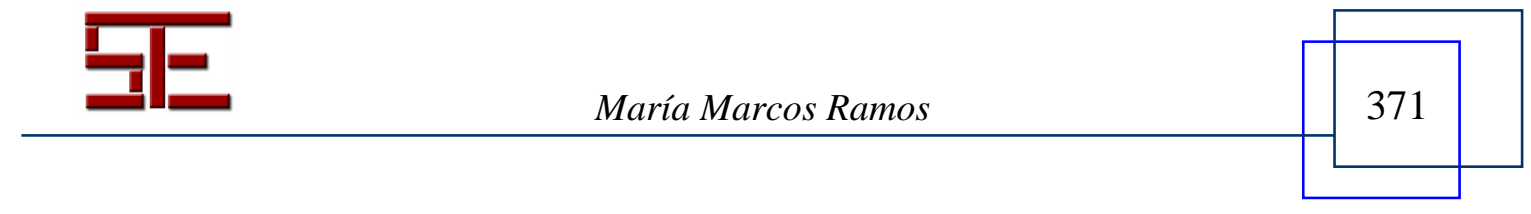




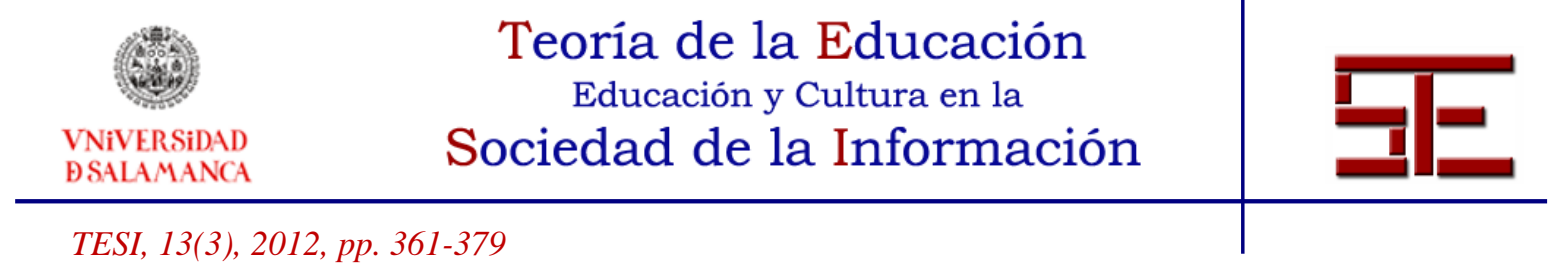

Para bien o para mal, los medios de comunicación son uno de los grandes educadores, enculturizadores, de los niños y adolescentes -incluso de los adultos-. Por eso, debemos hacer que sean para bien, que se utilicen de manera constructiva. Dos de las múltiples acciones que pueden desarrollarse en la escuela para lograr una alfabetización digital serían la utilización del cine formativo y la educación audiovisual mediante el uso de programas educativos ${ }^{2}$. En los países desarrollados se ha generado una doble influencia en los diseños educativos y en los modelos curriculares: la inclusión sobre contenidos de alfabetización mediática o audiovisual y la reorganización del currículum educativo para articularse conjuntamente con los procesos educativos y de desarrollo del contexto cultural y mediático.

Tan fundamental es que se enseñe a leer en el centro escolar como que se enseñe a ver en un mundo cada vez más visual. Se trata de "educar para el uso de la televisión: formar espectadores conscientes, críticos y activos, capaces de programar su propio consumo y de realizar un uso eficiente de la televisión" (Pérez Tornero, 1994, 27). Ésta ha sido una de las vías que más se han impulsado por parte de las instituciones para fomentar una educación audiovisual: educar para el uso de la televisión. Chalvon, Corset y Souchon $(1982,103)$ señalan que es:

En la escuela donde se debería sobre todo aprender a ver la televisión. Y en primer lugar, a analizar sus códigos, ya que se trata de reconsiderar todo lo que las emisiones de televisión dan como natural y evidente, lo 'inverosímil' en que construyen sus sistemas de signos y que ellos contribuyen de esta forma a difundir y a imponer. La finalidad es llegar a una lectura consciente de las imágenes, donde lo implícito esté explícito.

Conscientes de esta carencia desde las instituciones educativas se han tomado medidas para resolver este "analfabetismo icónico"3. Son dos las vías que se han llevado a cabo: enseñar a leer la imagen -a ver la televisión- y enseñar a utilizar la imagen -a conocer los códigos internos de la imagen y del funcionamiento de la televisión-. Algunos expertos han denominado a estas dos posturas educar en la televisión y educar con la televisión. Según Joan Ferrés (1994, 121-122):

Una adecuada integración de la televisión en el aula supone atender dos dimensiones formativas: educar en la televisión y educar con la televisión. Educar en la televisión significa convertir el medio en materia u objeto de estudio. Supone educar en el lenguaje audiovisual, enseñar los mecanismos técnicos y económicos de funcionamiento del medio, ofrecer pautas y recursos para el análisis crítico de los programas (...) En definitiva, realizar una aproximación al medio desde todas las perspectivas: técnica, expresiva,

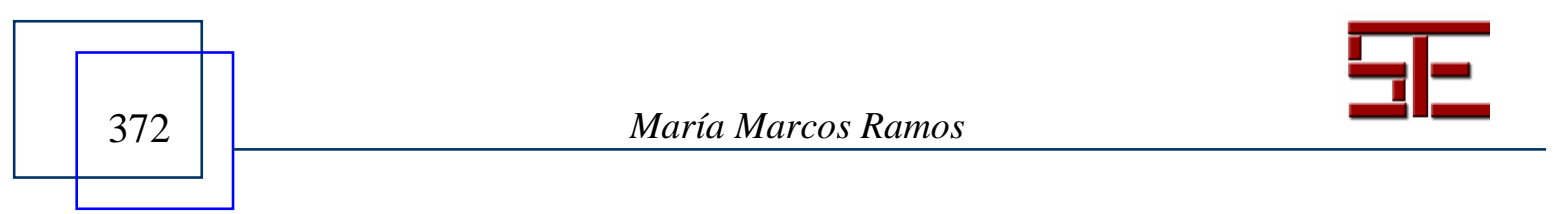




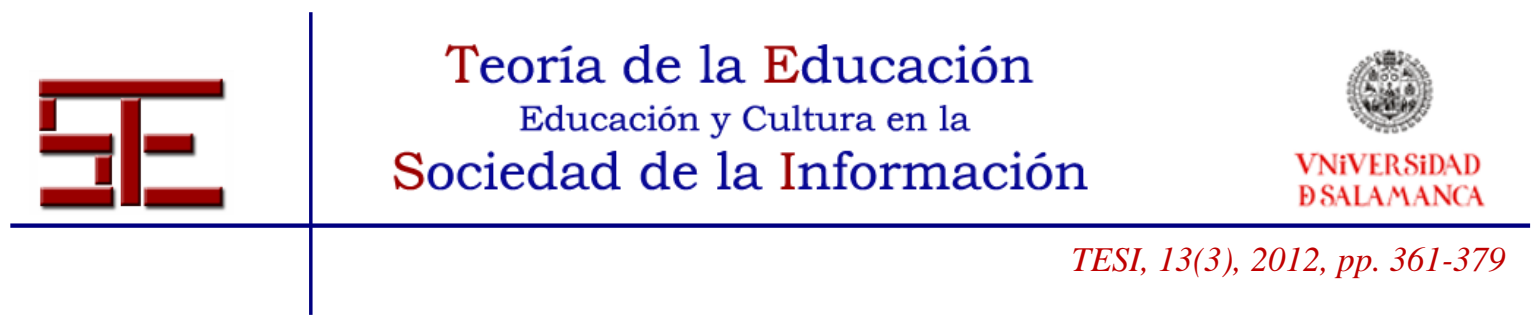

ideológica, social, económica, ética, cultural (...) Educar en la televisión. Pero también educar con la televisión. Incorporarla al aula, en todas las áreas y niveles de la enseñanza, no para incrementar aún más su consumo, sino para optimizar el proceso de enseñanza-aprendizaje.

Educar en la televisión tendría como objeto estudiar la televisión como medio de comunicación, conocer cómo se trabaja en el medio, por qué se emiten unas imágenes y no otras, esto es, "conocer el sistema televisivo, aprendiendo sus códigos y lenguajes, analizando sus contenidos y valores, conociendo sus efectos e influencias" (Sánchez Noriega, 1997, 450). Todos estos contenidos se han recogido en una asignatura optativa denominada Comunicación Audiovisual ${ }^{4}$. Una vez adquiridos estos conocimientos técnicos, el alumno podrá hacer un uso racional del medio; es decir, debería

saber usar la televisión -y, sobre todo, tener la posibilidad de dirigir racionalmente ese uso (como debe pretenderse desde la educación)- requiere, en primera instancia, un conocimiento reflexivo, conceptual y, en segundo lugar, creatividad, capacidad para concebir nuevas combinaciones y nuevas relaciones entre sus diversos elementos. Si no se dan estas circunstancias -instintos- sólo estaremos ante un uso rutinario y automático del televisor (Pérez Tornero, 1994, 39).

Una vez que se interioricen estos códigos internos del medio -tanto de la televisión como de otros medios: prensa, radio, Internet...- por parte de los receptores, se habrá aprendido a leer. Este saber leer "es fruto del aprendizaje -más o menos consciente- y es una actividad mental compleja que estimula el raciocinio, la lógica y la imaginación" (Pérez Tornero, 1994, 94).

Babin y Kouloumdjian (1983, 74-75) señalan que un proceso de análisis de los mensajes debe ir acompañado de una "elaboración de sentido" y especialmente de un "distanciamiento" proporcionado, por diferentes vías: la reflexión -sobre lo sentido y vivido-; por la conceptualización -por el paso a las ideas universales-; por la apropiación -o la reconstrucción en su propio lenguaje- $y$, finalmente, por el juicio crítico sobre los contenidos, la forma, el lenguaje, la técnica, los procedimientos utilizados, la infraestructura comercial y económica puesta en juego...

Miguel Reyes (1993), por su parte, realiza una propuesta de educación del telespectador centrada en tres grandes áreas: la desmitificación -conocer y apreciar el medio televisivo para aproximarlo como realidad al escolar telespectador-; la alfabetización conocimiento y dominio del lenguaje de la televisión-; y el autoanálisis-toma de conciencia de las necesidades, motivaciones y reacciones que produce la televisión en el telespectador.

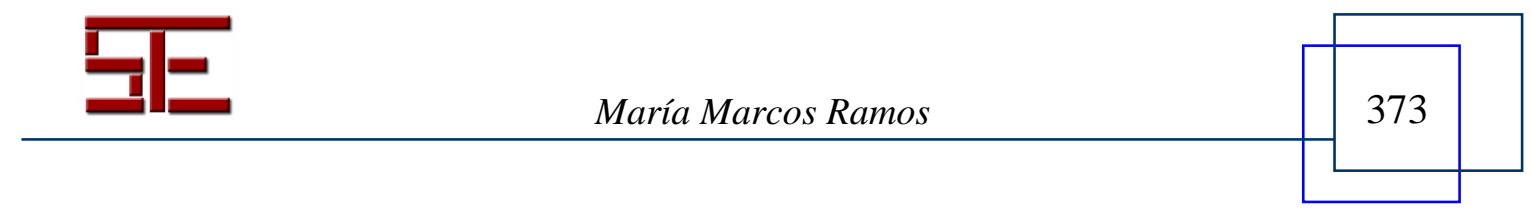




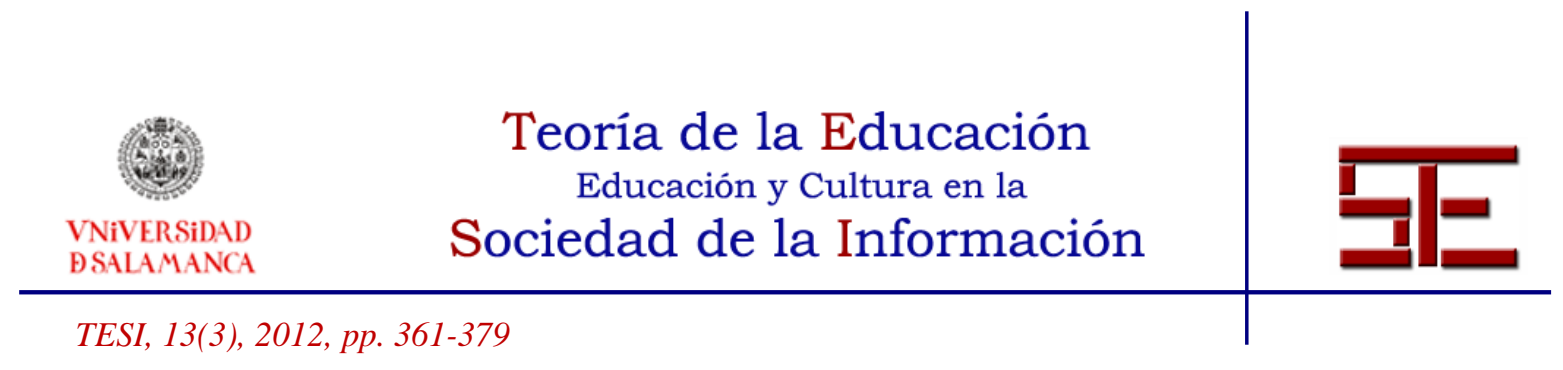

Pérez Tornero (1994, 153-156) establece una serie de propuestas para educar a ver la televisión. Estas propuestas las divide entre situaciones críticas y operaciones críticas. Dentro de las situaciones críticas propone:

- Situaciones de diálogo, que permitan verbalizar el visionado de los programas para reinterpretarlos, para asegurarse la pluralidad de perspectivas y para distanciarse del propio lenguaje de la televisión.

- Estrategias de comparación, ya que comparar es hacer un ejercicio de intertextualidad y de confrontación, que permite situar el sentido de los textos televisivos, confrontándolos con otros, hallando semejanzas y diferencias, fórmulas de captación de la atención, estilos comunicativos... esto es, descubriendo sus estrategias de comunicación.

- Procesos creativos, de forma que se afronte imaginativamente la televisión para fantasear libremente aprovechando los elementos que nos proporciona la televisión para aportar nuestra subjetividad y nuestra creatividad.

- Propuestas de confrontación de datos, puesto que hay que buscar fórmulas que permitan a los alumnos contrastar las informaciones del medio que, si bien quieren presentar como totémicas y únicas, nos obligan a desarrollar otras miradas en las que se ponga en evidencia que la televisión no es el mundo, sino un camino -entre otros- para acceder a su conocimiento.

- Dinámicas de exploración formal, que faciliten el conocimiento de las estéticas de los mensajes, de sus estructuras estilísticas, de los recursos estéticos del medio, puesto que se trata de interponer entre nosotros y el lenguaje de la televisión otros lenguajes, ya no verbales, sino plásticos, musicales...

- Pautas para la manipulación del medio, ya que el mensaje televisivo puede convertirse en nuestras manos en materia prima, en una oportunidad para el collage, la recreación, la resituación de todos sus elementos.

Para las operaciones críticas, entendidas "como los procesos que conducen a la lectura crítica", Pérez Tornero establece las siguientes actividades (1994, 156):

- Racionalización de su uso ${ }^{5}$, ya que éste ha de adaptarse necesariamente a las necesidades, intenciones y proyectos de cada individuo. En este sentido, es trascendental que los alumnos se planteen los propósitos que nos llevan a ver televisión, a analizar la correspondencia de éstos con lo que nos ofrecen las pantallas y evaluar la posibilidad de consecución de nuestro deseos. Para ello será necesario

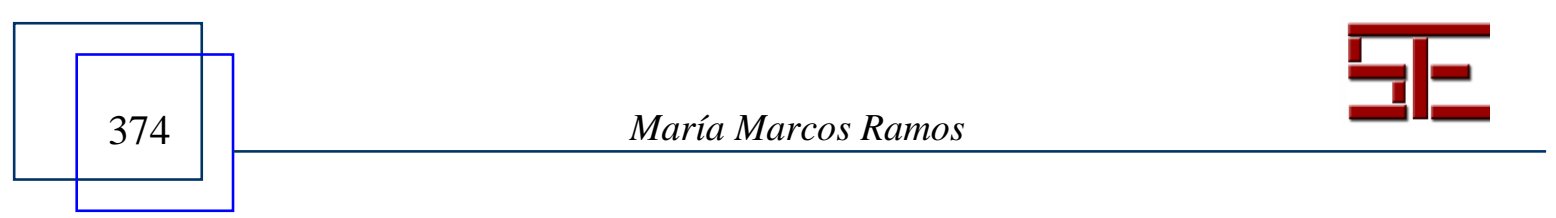




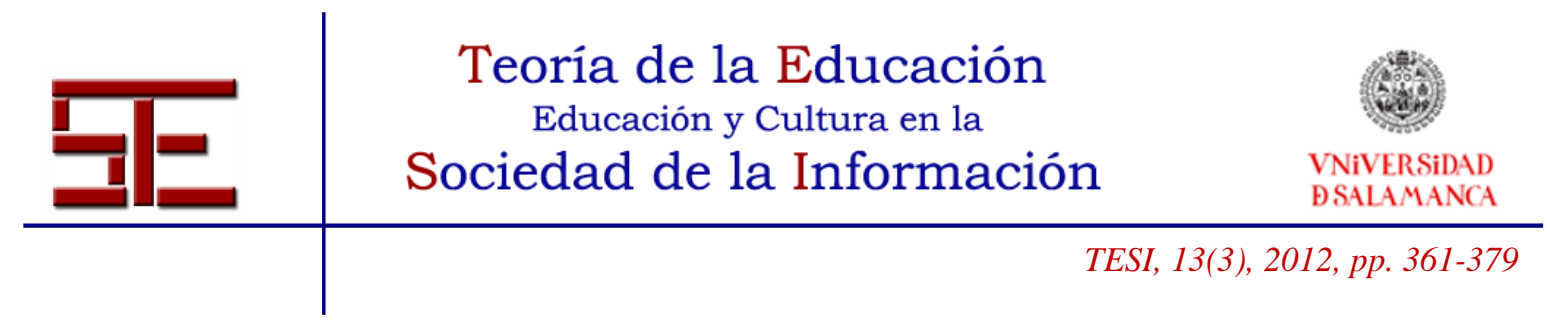

interpelarse personal y grupalmente por los horarios, la periocidad, la frecuencia, la gobernabilidad del consumo, el contexto en que se produce, las informaciones previas que obtenemos, la confrontación con otras posibilidades de ocio, etc.

- La creación de contextos adecuados para el visionado, dotando a los espacios de suficientes medios que faciliten el análisis. Serían interesantes y necesarias la existencia de mediatecas y la potenciación de los magnetoscopios ${ }^{6}$ y videocámaras para actividades de recreación y producción.

- El consumo colectivo y su verbalización, ya que el visionado aislado invita más a la hipnosis y a seguir unilateralmente el discurso del medio. Por ello, la discusión, la crítica colectiva, la diversidad de perspectivas que ofrece la puesta en común son estrategias básicas que hay que fomentar.

- La potenciación de la dimensión pública de la televisión, ya que sólo en este caso el medio puede abandonar, al menos parcialmente, su dimensión de espectáculo y subjetividad y convertirse en un recurso de integración social.

- El desarrollo de los juegos lingüísticos que permitan que la televisión pueda ser ironizada, resumida, glosada, contrastada, argumentada y contra argumentada, replicada y contradicha, afirmada y negada, provocada y estimulada... Todo ello engrandece el campo de acción del telespectador y ayuda a tomar distancia y facilitar la actividad creativa.

En el Informe Pigmalión recogen los autores una serie de recomendaciones a tener en cuenta por los programadores, señalando que es preciso tener en cuenta tres programaciones culturales:

- En primer lugar, la dieta audiovisual global, lo que podríamos denominar el currículo nacional de un país o una cultura desde el punto de vista del cultivo. Es decir, qué programación u oferta acumulada general, año tras año a lo largo del desarrollo de cada generación, está en el espacio audiovisual general (en la semiosfera de Lotman, o en la iconosfera de Gubern). Hay aquí un espacio prioritario para las políticas culturales nacionales, autonómicas y locales, y para la creación cultural desde un punto de vista de diseño cultural.

- En segundo lugar, es preciso contemplar de manera activa la dieta audiovisual global, entendiéndola como el conjunto formado por iniciativas públicas y privadas de dietas audiovisuales programadas. A las que debe verse constructivamente como un conjunto, potencialmente orquestal (no orquestado) de programas diseñados constructiva y conscientemente a corto, medio y largo plazo, desde la independencia y la responsabilidad. Es importante introducir las ideas de diseño y de creación+investigación formativa, que constituirían una corriente cultural activa, diversa pero coherente, en el escenario audiovisual. El espacio americano en el que se que habla castellano y lenguas latinas próximas configura una semiosfera geocultural muy especial en que podría (y debería) ejercerse esa creación cultural desde el diseño creativo e investigador responsables.

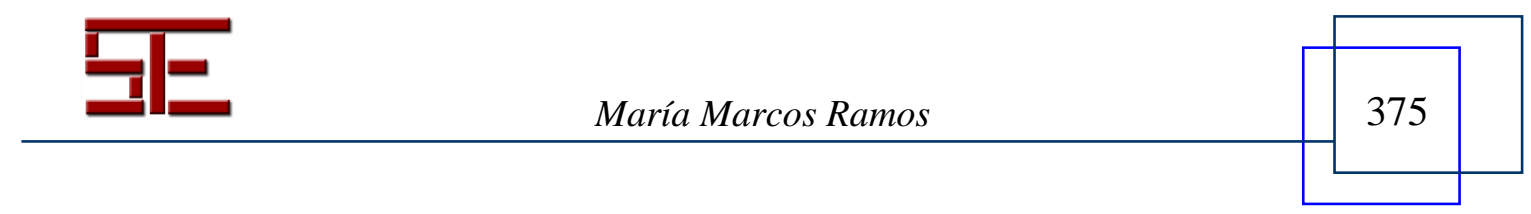




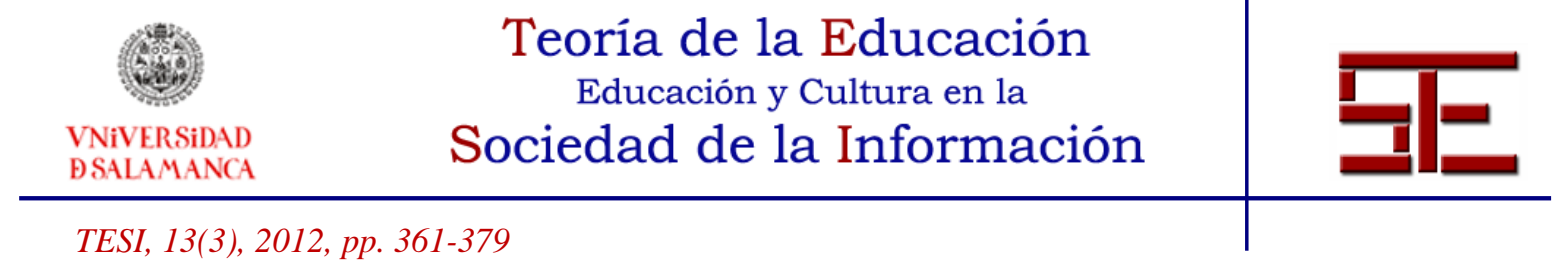

- En tercer lugar, la dieta audiovisual individual, ontogenética, de un niño, (muy unida a la de un grupo de hermanos en el contexto familiar). Estamos aquí ante el programa o currículo cultural personalizado. A ella se llega, partiendo de la dieta global, con el juego de factores eco-culturales y familiares. La escuela puede jugar un papel regulador central que hasta ahora, en general, no ha jugado; así como programas especiales transversales (Del Río, Álvarez, Del Río, 2004).

Estos mismos autores señalan en las conclusiones de su informe que:

Se hace necesario un plan de acción destinado a reforzar la producción de modelos audiovisuales que promuevan el conjunto de factores cuya ausencia repercute en los comportamientos antisociales y violentos: el control de la conducta voluntaria y la disciplina; la empatía, la identificación con el otro y la resonancia emocional con los demás; la orientación hacia las narrativas y modelos dramáticos prosociales; y las estructuras cognitivas (reglas o modelos) para sustentar el juicio moral (Del Río, Álvarez, Del Río, 2004).

\section{5.- CONCLUSIONES}

Tras los resultados obtenidos con la encuesta realizada y una vez analizados los datos, se ha demostrado que son necesarias una alfabetización mediática y una mediación parental a la hora de consumir determinados productos. La pregunta que instituciones, padres, educadores, etc., se hacen es si la televisión y, por extensión, otros medios, crean espectadores violentos. La respuesta es sí. Según los estudios realizados, la televisión nos hace violentos, pero no es la única culpable. La falta de educación audiovisual, la falta de maduración, la falta de "buenos" referentes, la falta de mediación parental, etc., hacen a la televisión $-\mathrm{y}$ por ende a los demás medios de comunicación- menos culpables. Es más sencillo echar la culpa a la televisión de todo aquello que sucede en la sociedad que mirar los errores que cometemos. No es la única culpable, pero sí debemos vigilarla de cerca para que sea menos culpable. En este trabajo se ha demostrado que es necesario que los niños reciban una educación mediática y que los adultos realicen en los hogares estrategias de mediación y contextualización. Es necesario, por tanto, enseñar a "leer" los contenidos mediáticos y aprender a utilizarlos, fomentando la empatía cuando sea necesario y distanciando al espectador con comentarios críticos cuando así se necesite.

\section{6.- BIBLIOGRAFÍA}

Babin, P. \& Kouloumdjian, M. F. (1983). Les nouveaux modes de comprendre. La génération de l'Audiovisuel et de l'Ordinateur. Lyon: Éditions du Centurion.

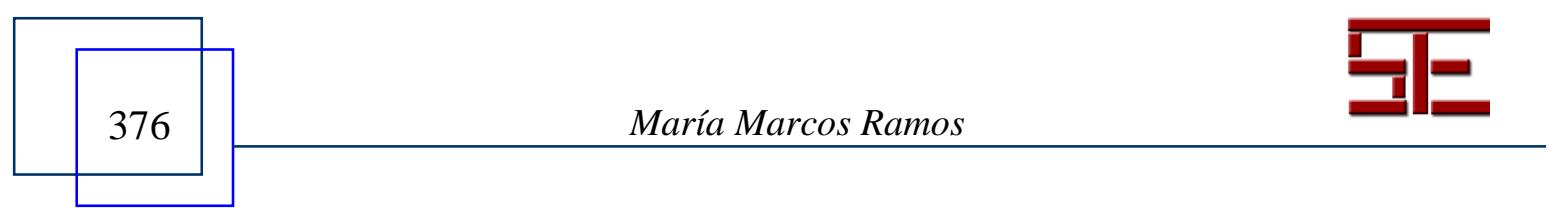




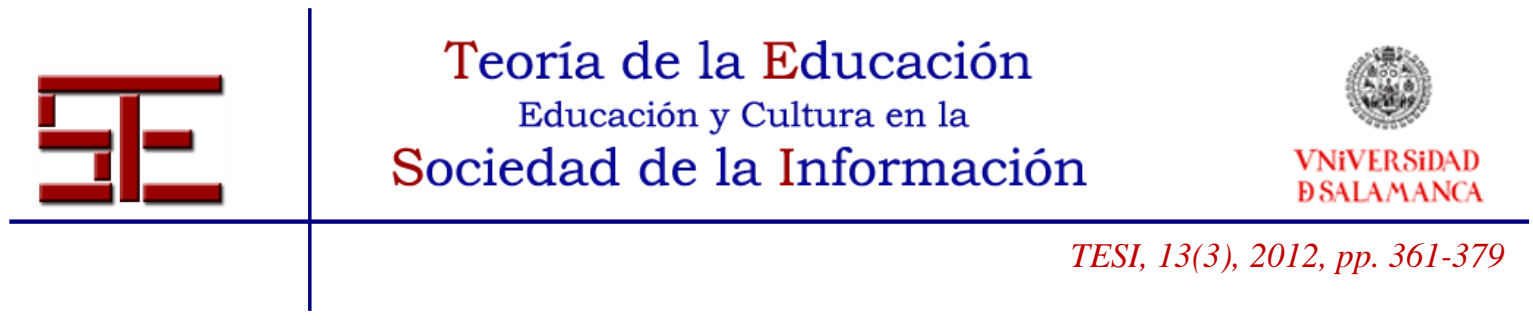

Bandura A. (1977). Social Learning Theory. New York: Prentice Hall.

Bandura, A., Ross, D., \& Ross, S.A. (1961). Transmission of aggression through imitation of aggressive models. Journal of Abnormal and Social Psychology, 63, (575582). Washington: American Psychological Association.

Berkowitz, L. (1965). The concept of aggressive drive: some additional considerations. En L. Berkowitz (Ed.), Advances in Experimental Social Psychology, vol. 2. New York: Academic Press.

Chalvon, M., Corset, P. y Souchon, M., (1982). El niño ante la televisión. Barcelona: Juventud.

De la Torre, S. (1997). Cine formativo.Una estrategia innovadora para los docentes. Barcelona: Ediciones Octaedro.

Del Río, P., Álvarez, A. \& Del Río, M. (2004). Pigmalión. Informe sobre el impacto de la televisión en la infancia. Madrid: Fundación Infancia y Aprendizaje.

Drabman. R. S., Thomas, M. H. (1974). Does media violence increase children's toleration of real-life aggression? Dev Psychol. 10 (3), (418-421). University of Michigan.

Ferrés, J. (1994). Televisión y educación. Barcelona: Editorial Paidós.

Feshbach, S. \& Singer, R. D. (1971). Television and aggression: An experimental field study. Washington: Jossey-Bass.

Geen, R. G., O’Neal, E. C. (1969). Activation of cue-elicited aggression by general arousal. Journal of Personality and Social Psychology, 11, (289-292). Indiana University.

Huesmann, L. R., \& Eron, L. D. (1986). Television and the Aggressive Child: A CrossNational Comparison. Hillsdale, NJ: Lawrence Erlbaum Associates.

Igartua, J. J. (2006). Métodos cuantitativos de investigación en comunicación. Barcelona: Paidós.

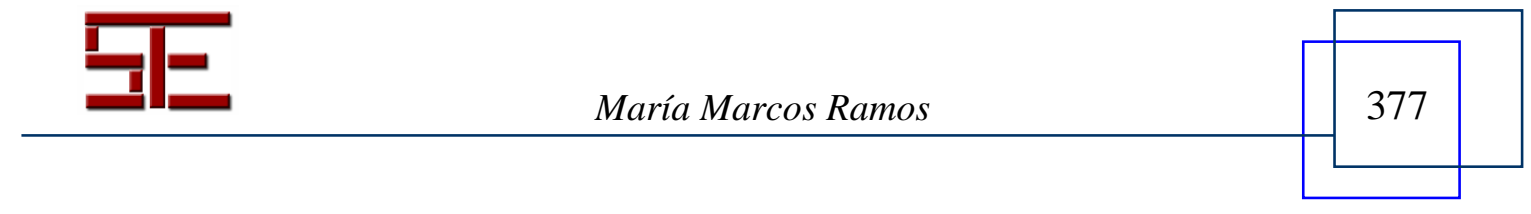




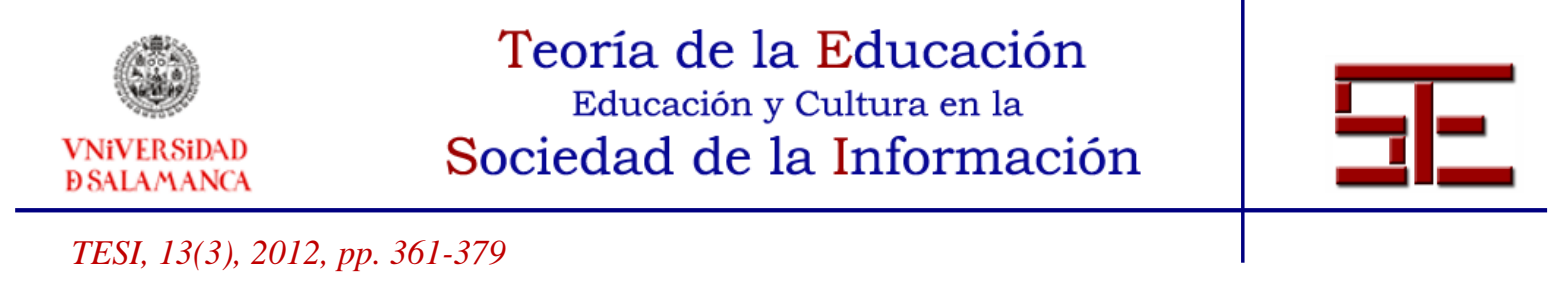

Lefkowitz, M. M., Eron, L. D., Walder, L. D. \& Huesmann, L. R. (1977). Growing Up to Be Violent. New York: Pergamon Press.

Liebert, R. M., Neale, J. M. y Davidson, E. S. (1976). La televisión y los niños. Barcelona: Editorial Fontanella.

Olson, D. (1995). Writing and the mind. En J. V. Wertsch, P. del Río y A. Álvarez (Eds.), Sociocultural studies of mind (pp. 99-123). Cambridge, MA: Cambridge University Press.

Pérez Tornero, J. M. (1994). El desafío educativo de la televisión. Para comprender y usar el medio. Barcelona: Paidós Papeles de Comunicación.

Potts, R., Huston, A. C. \& Wright, J.C. (1986). The effects of television for and violent content on boys' attention and social behaviour. Journal of Experimental Child Psychology, 41, 1-17.

Reyes, M. (1993). La tarea de la Educación para la comunicación. Del otro lado de la imagen. Selección de ponencias presentadas al Séptimo Encuentro "El Universo Audiovisual del Niño Latinoamericano”. La Habana, Cuba.

Sánchez Noriega, J. L. (1997). Crítica de la seducción mediática. Madrid: Tecnos. (2007). Los lenguajes de las pantallas: del cine al ordenador. Madrid: MEC.

Thomas, M. H., Horton, R.W., Lippincott, E. C. \& Drabman, R. S. (1977). Desensitization to portrayals of real-life aggression as a function of exposure to television violence. Journal of Personality and Social Psychology, 35 (6), (450-458). Indiana University.

Wimmer, Roger D. \& Dominick, Joseph R. (1996). La investigación científica de los medios de comunicación. Una introducción a sus métodos. Barcelona: Bosch Editorial.

\section{Notas}

${ }^{1}$ Cobardes está clasificada como no recomendada para menores de 12 años. En España, tal y como señala el Ministerio de Cultura, toda película antes de ser comercializada debe presentarse en el ICAA o en la Comunidad Autónoma pertinente para su calificación por grupos de edad del público al que van

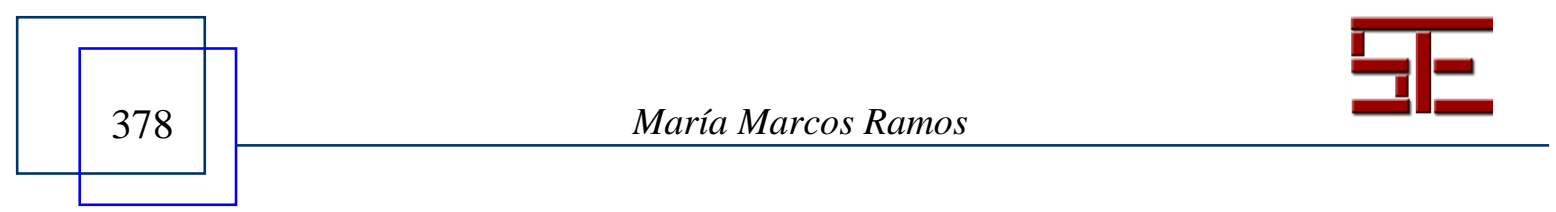




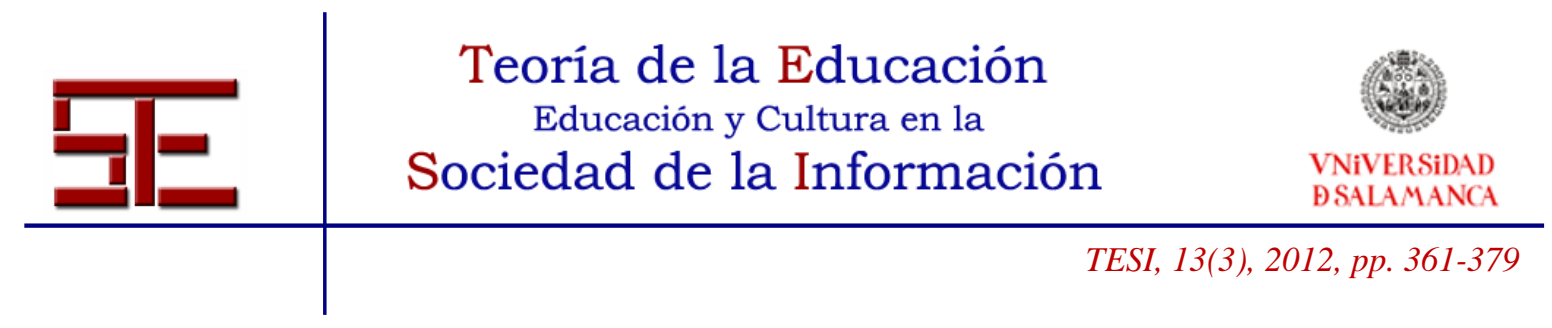

destinadas. Dicho criterio es sólo orientativo, excepto en las películas clasificadas como X, que se exhibirán únicamente en salas especiales denominadas «Salas $\mathrm{X}$, $\mathrm{y}$ en caso de comercialización no cinematográfica deben presentarse al público en lugares especiales no accesibles a menores.

${ }^{2}$ En el hogar, la educación visual puede realizarse mediante el uso por parte de los padres de la mediación, además de la visualización de programas educativos.

${ }^{3}$ Umberto Eco ya señaló hace más de tres décadas que "la civilización democrática se salvará únicamente si hace del lenguaje de la imagen una provocación a la reflexión crítica, no una invitación a la hipnosis" (Eco, 1968).

${ }^{4}$ A principios de los años 90 aparece en el Currículo la materia Comunicación Audiovisual, con carácter optativo. En 2007, el Real Decreto 1467/2007 define los objetivos, contenidos y criterios de una nueva asignatura, Cultura audiovisual, que parecía que vendría a sustituir a la anterior. Hoy en día, conviven las dos asignaturas aunque no se ofertan en todos los centros ni para todos los Bachilleratos, sólo en el de Artes.

${ }^{5}$ Es fundamental a la hora de trabajar este aspecto contar con la colaboración de los padres ya que de "ellos dependen en cierta medida los modelos de referencia que los alumnos adquieren e imitan" (Aguaded, 2005, 54).

${ }^{6}$ Hoy en día, este problema de dotación tecnológica está prácticamente solucionado con la implantación en las aulas de la pizarra digital. De esta manera, con un ordenador y con la pizarra digital el aula está dotada tecnológicamente para la reproducción de contenidos audiovisuales.

Para citar el presente artículo puede utilizar la siguiente referencia:

Marcos Ramos, M. (2012). ¿Por qué es necesario realizar una educación mediática? Un análisis de caso con la película Cobardes. Revista Teoría de la Educación: Educación y Cultura en la Sociedad de la Información. 13(3), 361-379 [Fecha de consulta: $\mathrm{dd} / \mathrm{mm} / \mathrm{aaaa}]$.

http://campus.usal.es/ revistas_trabajo/index.php/revistatesi/article/view/9145/9378

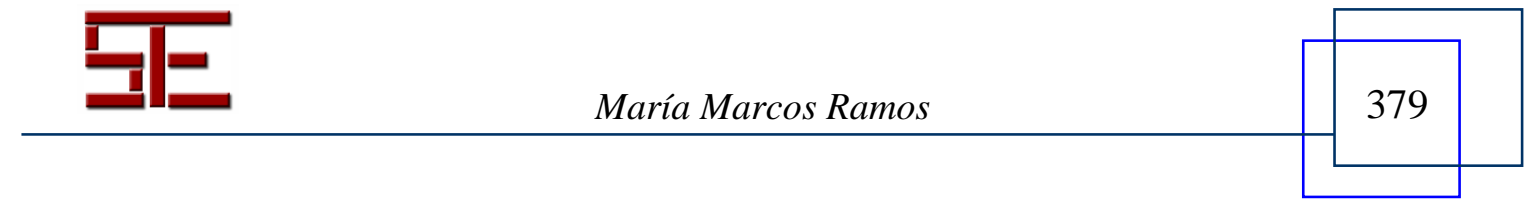

